\title{
La crisis de las relaciones atlánticas y la formación de un "centro" europeo (1968-1975); un ensayo interpretativo
}

\section{I. 'Grisis de las relaGiones atLÁNticas}

A través de la década del 50 y los primeros años de la del 60, se manifestó un designio de Estados Unidos de contribuir a la reconstrucción de la economía europea mediante exportaciones de capital y tecnología, así como alentando la integración europea. A cambio, los Estados Unidos pudieron manejar libremente las políticas de seguridad del bloque occidental y gozaron de los beneficios de señorazgo derivados del uso del dólar en el sistema monetario internacional. Pero la relación atlántica no era ajena al conflicto. El arancel externo común y la política agrícola de las Comunidades Europeas resultaron fuentes de antagonismo por su discriminación hacia las exportaciones norteamericanas. Por ejemplo, en 1960, las Comunidades Europeas, tratando de proteger la agricultura de sus estados miembros, se negaron a garantizar a los Estados Unidos una cuota fija de sus mercados de granos, como había venido ocurriendo en años anteriores, sin tomar en consideración las ocasiones en que Europa alcanzaba una producción suficiente en el rubro.

Otras evidencias de conflicto aparecieron cuando el gran proyecto de Kennedy de una Alianza Atlántica y su disposición para dialogar con Europa acerca de la implementación de una estrecha asociación, se encontraron con un rechazo europeo, en gran parte debido a la insistencia norteamericana en la centralización del control estratégico dentro de la Alianza. El conflicto se hizo aún más perceptible a mediados de los 60, cuando Francia se retiró de la OTAN aduciendo que esta organización era manejada de acuerdo con los intereses norteamericanos, los cuales no eran necesariamente coincidentes con los de Francia y los demás países europeos.

Sin embargo, fue solamente a fines de la década del 60, bajo el Gobierno de Nixon, que las fricciones entre Estados Unidos y Europa adquirieron una dimensión crítica.

Entre 1952 y 1968, la participación norteamericana en la riqueza mundial habia disminuido de $50 \%$ a $33 \%$, debido principalmente 
a los incrementos obtenidos por países como Alemania, Francia y Japón, que eran aliados de Estados Unidos, que disfrutaban de un tratamiento especial por parte de esta nación. En 1968 y 1969, en la fase más intensa de la guerra del Vietnam, la balanza de pagos norteamericana declinó dramáticamente.

La fuerza económica y la competitividad de Europa y Japón fueron agudamente sentidas por la economía norteamericana. En el aspecto comercial, los norteamericanos retenían la hegemonía en cuanto a productos de alta tecnología, tales como aviones y computadoras, pero en el campo de los bienes de menores requerimientos tecnológicos, por ejemplo aparatos electrónicos y automóviles, Estados Unidos se había convertido en importador o en frustrado competidor. Esta situación indicaba sencillamente que no había perspectivas cercanas de arreglo para el déficit de balanza de pagos norteamericano.

Las reservas de oro de Estados Unidos decrecian sustancialmente (26 billones de dólares en 1949; 12 billones de dólares en 1971) y al desequilibrio fundamental del sector externo había que agregar grandes saldos de dólares en manos de Europa y Japón, que alimentaban la presión sobre la economía estadounidense y el dólar.

Desde 1880, los Estados Unidos habían sido holgadamente autosuficientes en términos de bienes y capital; por ello, la invasión de sus mercados por productos foráneos tuvo un severo impacto sobre la producción nacional. La afectada sensibilidad de la economía norteamericana produjo generalizados sentimientos de xenofobia $y$ de frustración hacia los aliados "ricos y egoístas" que contribuían solamente con la mitad de lo que aportaba Estados Unidos para la defensa de Occidente (Buchan 1974). Los reclamos de poderosos grupos económicos contra la liberal política comercial norteamericana se hicieron escuchar fuertemente.

La doctrina Nixon intentó responder a estas presiones internas planteando un explícito abandono de la posición norteamericana durante toda la guerra fría, así como el establecimiento de una nueva relación con sus principales aliados, gravitando sobre el supuesto fundamental de que el sistema económico internacional funcionaba en perjuicio de los Estados Unidos. La doctrina Nixon involúcró una reducción de los compromisos externos norteamericanos y una definición de los intereses nacionales en términos menos ambiciosos y universales que los que habían prevalecido hasta entonces, según Nixon expuso al Gongreso en 1970 (Guesau 1974).

Concretamente, la doctrina Nixon motivó dos drásticas medidas económicas adoptadas en agosto 1971: un gravamen de $10 \%$ a las importaciones y la declaración de no convertibilidad del dólar. Ambas medidas tuvieron duraderas consecuencias políticas y económicas. La primera de ellas, no obstante haber sido suprimida a fines 
del mismo año, significó un duro golpe para Europa y Japón. La segunda decisión condujo al Acuerdo Smithsoniano entre Estados Unidos, Europa y Japón, en virtud del cual el dólar fue en realidad devaluado en un $10 \%$, a través de la concertada revaluación de los demás signos monetarios de importancia en el mundo industrializado. Este Acuerdo marcó el final del Sistema de Bretton Woods.

En el aspecto político, Nixon buscó un mayor acercamiento con las dos potencias comunistas, primero con la Unión Soviética y posteriormente con China.

Desde la década del 60 se había hecho evidente que los Estados Unidos y la Unión Soviética tenían una relación, bien de conflicto o de cooperación, que era mury distinta de aquellas que cada uno tenfa con sus respectivos aliados (la crisis de los misiles en Cuba, manejada unilateralmente por Estados Unidos, el Tratado de Proscripción de las Pruebas Atómicas Atmosféricas (1963) y la instalación de una línea telefónicia de emergencia entre Washington y Moscú, fueron algunos ejemplos de esta relación especial). Las suspicacias, que hacían referencia a una colusión o una hegemonfa dual de ambas potencias sobre el mundo, se tornaron más agudas cuando la distensión política fue seguida por una política norteamericana de cooperación con la Unión Soviética en los campos de comercio, ciencia y tecnología (1971-1972). Esta iniciativa estadounidense halló a una Unión Soviética ávida por cosechar los frutos económicos de la nueva relación.

Por otro lado, en Europa la década del 60 estuvo dominada por una nítida percepción del "desafío americano" y por un esfuerzo conjunto de los miembros de las Comunidades Europeas por ponerse a la altura de la industria norteamericana, el cual se implementó con una política industrial común y con la planificación conjunta de las actividades de investigación y desarrollo (Haas 1976). Los esfuerzos, sin embargo, se realizaban en estrecha asociación con compañías norteamericanas, las cuales en gran número se establecieron en Europa y dirigieron su producción tanto a Ios mercados europeos como al de Estados Unidos. Este fenómeno determinó una curiosa situación en los últimos años de la década del 60, cuando frente a una exacerbada sensibilidad norteamericana, debido a la oleada de productos europeos, coexistía un resentimiento por parte de los países europeos en virtud de la creciente absorción de industrias nacionales por empresas norteamericanas.

Al final de la década del 60, las Comunidades Europeas estaban preparadas para dar un salto importante en su-evolución. La crisis de 1965, provocada por el desacuerdo de Francia acerca del financiamiento de la política agrícola y por su oposición al fortalecimiento de las instituciones comunitarias, había sido completamente superada y el reemplazo de De Gaulle por Pompidou (1969) hizo por 
fin posible aumentar el número de Estados miembros de seis a nueve. El ingreso de Inglaterra, Dinamarca e Irlanda (1973) convirtió a las Comunidades en una organización mucho más representativa de los intereses de Europa occidental, apta para negociar con los Estados Unidos, los cuales por muicho tiempo tuvieron el deseo de tratar con una contraparte de esta envergadura.

Desafortunadamente, el momento económico por el cual atravesaba Estados Unidos, económicamente debilitado y sensibilizado por la competencia externa, no constituía para este país la mejor ocasión para llegar a acuerdos con un grupo próspero de naciones que además estaba ligado, a través de acuerdos preferenciales, con un gran número de países de intermedio y escaso desarrollo. Tampoco se encontraba Europa en su mejor momento para negociar con Estados Unidos; debido a su preocupación por el dominio norteamericano de las industrias europeas y sobre todo por su alarma frente a las negativas implicancias que podía tener para su seguridad la distensión entre las superpotencias.

En la Cumbre de París de 1972, que fue la primera reunión de los jefes de estado de las Comunidades ampliadas, el objetivo principal fue la creación de una Unión Económica y Monetaria Europea. A la sazón, esta parecía ser una opción inevitable en vista del persistente desorden del sistema monetario internacional. El Acuerdo Smithsoniano habia cambiado muy poco la situación, por cuanto en 1972 los Estados Unidos venían arrastrando un déficit comercial aún mayor que en 1971

La primera etapa de la Unión Monetaria conllevaba la creación de un Fondo Monetario Europeo y el alineamiento de los signos monetarios de los estados miembros. La flotación conjunta de las monedas europeas (fenómeno denominado "serpiente europea") constituyó en realidad una reacción directa frente a una segunda crisis monetaria y a una nueva devaluación del dólar (marzo 1973) y determinó el fin del sistema de compra automática de dólares en los mercados europeos por los bancos centrales. De esta manera, Europa se negó a continuar extendiendo crédito al Tesoro norteamericano, que había estado usando este mecanismo para aliviar su enorme déficit de balanza de pagos, disponiendo de recursos extranjeros con el simple expediente de crear obligaciones en dólares (Hudson 1977) . El resultado de estas acciones fue la caída del dólar frente a la libre flotación de las monedas europeas.

La reacción norteamericana se tradujo en un discurso del Secretario de Estado Kissinger (abril 1973), en el cual insinuó que si Europa no se mostraba más dispuesta a cooperar en asuntos comerciales y monetarios, así como a compartir los gastos de la otan (que en ese momento resultaban para los Estados Unidos una carga económica excesiva a la luz del firme avance de la distensión), el Go- 
bierno norteamericano tendría que reconsiderar el despliegue de sus recursos comprometidos con la seguridad europea. Kissinger observó que la unidad europea no debía ser un fin en sí mismo sino un medio para el fortalecimiento de Occidente y, por lo tanto, se mostraba en desacuerdo con la perspectiva de crear un bloque cerrado de comercio que comprendiera las Comunidades Europeas, las naciones mediterráneas y el Africa y que funcionara en detrimento de Estados Unidos y otras naciones.

Kissinger enfocó sobre todo la necesidad de nuevos acuerdos económicos, en el marco de una nueva Carta Atlántica, todo lo cual debía alcanzarse a través de negociaciones bilaterales entre Estados Unidos y cada gobierno europeo (Hudson 1977).

Aunque no hubo respuesta inmediata al discurso de Kissinger por parte de ningún gobierno europeo, los diarios reflejaron el rechazo general a la vinculación de los asuntos económicos, monetarios y militares en un solo paquete como base de negociación. La Declaración sobre la Identidad Europea (DrE), emitida por la Cumbre de Gopenhague en septiembre de 1973, representó una respuesta conjunta a la propuesta norteamericana, en la cual los países europeos recalcaron su intención de convertir a Europa en una entidad diferenciada en los asuntos mundiales y en un socio dispuesto a cooperar con Estados Unidos sobre una base de igualdad. Un año más tarde, en seguimiento de esta determinación, se comisionó a varias instituciones comunitarias la elaboración de sendos informes que delinearan el camino a seguir por Europa para llegar a ser una tercera fuerza en el contexto de la distensión soviético-norteamericana. El Informe Tindemans, que representa un hito en la evolución de las ideas acerca de la unificación europea, condensó estos informes en 1975. Tindemans presenta básicamente una serie de propuestas para transformar las relaciones entre los países europeos, ampliando su campo de acción y fortaleciendo la acción colectiva. La Unión de Europa debe significar fundamentalmente que los estados miembros muestren un frente unido al resto del mundo, y esto se puede obtener solamente ạ través de políticas comunes en ciertas áreas cruciales, sobre todo las relaciones externas, las cuales deben ser al mismo tiempo económicas, industriales, financieras, comerciales y políticas. En este último campo, ya en 1971 se había creado la Conferencia de Ministros de Relaciones Exteriores y un Comité Politico, como estructura institucional encargada de desarrollar la cooperación política, de manera paralela a la integración económica y de llegar a establecer una política común exterior europea.

Estados Unidos, por su parte, continuó sus acciones unilaterales, embargando las exportaciones de 40 productos agrícolas, invocando el designio de contener la inflación interna. Esta acción hizo comprender a los países europeos y al resto del mundo que el acceso 
foráneo a los alimentos producidos en Estados Unidos requeriría en el futuro no solamente que la producción en ese país superara al consumo sino que también hubiera perspectivas de mantener relativamente estables los precios internos.

En octubre de 1973, durante la guerra árabe-israeli, los países árabes productores de petróleo impusieron un embargo a las exportaciones de petróleo dirigidas a los Estados Unidos, Holanda y Dinamarca, con el objeto de presionar a estos países para que retiraran su apoyo a Israel. Amenazados por la posibilidad de medidas similares, los demás gobiernos europeos, señaladamente Inglaterra, Francia, Alemania e Italia, adoptaron una posición distinta a la de Estados Unidos frente al conflicto. Inglaterra y Alemania rehusaron cooperar con las tropas norteamericanas para procurar ayuda a Israel e Italia llegó a pedir el retiro de las tropas judías de los territorios que habian ocupado. Hay que reconocer, sin embargo, que estas medidas representaban también la culminación de una línea pro-árabe mostrada por los gobiernos europeos desde 1967.

Después del alza de los precios del petróleo, en diciembre de 1973, los países europeos declinaron en principio unirse a Estados Unidos para formar un cartel de importadores de petróleo con miras a enfrentarse a la OPEP. En vez de ello, atendieron sus intereses particulares y concertaron arreglos bilaterales con los países árabes, asegurando la continuidad de sus suministros de energía. Más tarde, en la Conferencia de Washington sobre energía, en 1974, los países europeos, con Ia excepción de Francia, cedieron a las presiones norteamericanas para diseñar una política energética con un propósito global, pero no obstante, al mismo tiempo las Comunidades Europeas iniciaba el Diálogo Euro-Arabe, en el cual se planteaba un amplio marco de cooperación entre los dos grupos de paises.

\section{BASES PARA LA ACGIÓN GOMUNITARIA DE EuROPA}

\section{Inserción en el Sistema Internacional}

Los Estados Miembros de las Comunidades Europeas comparten una convicción fundamental de que ya no pueden ejercer individualmente la influencia que por muchos siglos ejercieron sobre el sistema internacional. Hoy en día los países europeos más poderosos son solamente potencias secundarias (Inglaterra, Francia y Alemania) o medianas (Bélgica, Italia y Holanda), muy distantes del poder de las superpotencias (Feld 1976). En la Declaración sobre la Identidad Europea (DIE) de 1973, esta convicción era claramente expresada:

"Aunque en el pasado los Estados Europeos estaban capacita- 
dos individualmente para desempeñar un rol de primera importancia en la escena internacional, los problemas mundiales que se presentan en la actualidad son difíciles de resolver para cualquiera de los Nueve actuando independientemente. Los acontecimientos internacionales y la creciente concentración del poder determinan que Europa deba unirse y hablar cada vez más con una sola voz si desea hacerse oír y desempeñar un rol apropiado en el mundo" (DIE, Boletín CE 197312).

Como señalara Buchan, Europa es la "región de las potencias medianas", las cuales para sobrevivir en su rol deben asociarse entre ellas, tal como siempre lo han hecho de una u otra manera a través de la historia (Buchan 1974). A mediados de la década del 70 el concepto de un mundo "pentapolar", propugnado por Nixon y Kissinger, implicaba para Europa la necesidad de jugar unitariamente un rol similar al de sus propuestos acompañantes en la cumbre del poder mundial, los cuales eran Chinà, la Unión Soviética, Japón y los Estados Unidos.

Una Europa unida podría alcanzar la fuerza y la influencia suficientes para tener impacto en el Sistema Internacional y tratar de modificarlo de acuerdo con ciertos principios fundamentales:

"la Comunidad, que es el más grande bloque comercia del mundo, no puede ser una entidad económica cerrada. Europa tiene estrechos vínculos con el resto del mundo en términos de suministros y mercados de exportación. Por esta razón, la Comunidad pretende... ejercer una influencia positiva sobre las relaciones económicas internacionales... (Europa) está consciente de que al unirse asume nuevas obligaciones internacionales. 'La unificación europea no está dirigida contra nadie ni está inspirada en un deseo de poder. Por el contrario, los Nueve están convencidos de que su unión beneficiará a toda la comunidad internacional, pues constituirá un elemento de equilibrio y una base para la cooperación con todos los países... los. Nueve pretenden desempeñar un rol activo en los asuntos mundiales y de esta manéra contribuir... a asegurar que las relaciones internacionales tengan una base más justa; que se preserve mejor la independencia e igualdad de los Estados; que se distribuya más equitativamente la prosperidad y que la seguridad de cada país sea más efectivamente garantizada" (DIE).

Europa se percata de que su importancia se deriva principalmente de las dimensiones de sus mercados, y que esto constituye su principal instrumento para aspirar a un rol destacado en la política mundial, sin buscar la confrontación con ninguna de las superpotencias sino más bien como una tercera fuerza de diferente natura- 
Javier Alcalde / La crisis de las relaciones atlánticas y la formación de un...

Ieza y con una finalidad equilibradora. Imbuida de un rol de potencia económica o "civil", Europa proclama especial interés por evitar el conflicto en el sistema internacional, tal como revela el informe Tindemans:

"El creciente poder político de los Nueve cuando actúan unidos y sus intereses por atenuar las fuentes potenciales de conflicto en las áreas adyacentes, tienden a inducir a actuar conjuntamente" (Boletín CE Sup. 1-76).

\section{Relaciones Interregionales}

Europa se mantiene desde un punto de vista estratégico en el centro del mundo, en una posición de significación clave y con un ambiente externo de bastante heterogeneidad. EI Viejo Continente se encuentra entre las dos superpotencias y al sur tiene, por un lado, el más grande conglomerado de países en desarrollo del mundo (Africa), y por otro, una constelación de países productores de petróleo que han conseguido un nuevo status de potencias energéticas y financieras sin haber experimentado mayores cambios en sus estructuras económicas. Más específicamente, las Comunidades constituyen la parte central tanto de Europa como de la región Mediterránea, donde existen otros Estados de diversas características.

Entre los actores de este heterogéneo ambiente externo hay tres que poseen una especial relevancia, pues participan como "sistemas intrusivos" en Europa: las dos superpotencias y los países productores de petróleo. Todos ellos tienen una significativa participación en las relaciones internacionales del sistema europeo, como corresponde a los "sistemas intrusivos" (Cantori \& Spiegel 1979).

En tanto que los Estados Unidos participan en los asuntos europeos a través de vínculos estratégicos, políticos y económicos con las naciones europeas, la Unión Soviética, como potencial antagonista de Europa, nación dominante del bloque comunista y poseedora de extraordinario poderío militar, origina relaciones que gravitan sobre todas las decisiones políticas de las naciones europeas y afectan muchas de sus preocupaciones económicas. Por otro lado, la participación de los países árabes productores de petróleo se ha vuelto particularmente intensa a partir del embargo petrolero y del alza de los precios de los hidrocarburos, a través de varios acuerdos bilaterales y multilaterales entre los dos grupos de países, en el marco del diálogo Euro-Arabe.

El rol de Estados Unidos tiene una importancia suprema debido a su participación económica y estratégica en la región, la cual origina considerable resentimiento en su primera modalidad, pero es vista como una opción inevitable frente a la continua amenaza militar de las fuerzas del Pacto de Varsovia. 
De conformidad con las ampliamente diversas características de los elementos de su ambiente externo, Europa exhibe un conjunto diferenciado de principios de política para sus relaciones con cada grupo de países, según se refleja en la DIE.

Con relación a Estados Unidos, Europa percibe que los estrechos lazos con su socio atlántico, sustentados en una herencia común de valores y aspiraciones, son mutuamente beneficiosos y deben preservarse. En efecto, uno de los vínculos más cohesionantes entre los mismos Estados europeos, así como con los Estados Unidos, es el deseo de cautelar su común tradición de civilización occidental, la cual Europa desarrolló y esparció por el mundo y que ahora se enfrenta a poderosos desafíos. Es preocupación de los Estados europeos "asegurar la supervivencia de la civilización que tienen en común" (lo cual podría ser interpretado por algunos como una versión "en retirada" del antiguo concepto colonialista de "la carga del hombre blanco").

Los países europeos anhelan que los valores occidentales orienten la estructura de las distintas sociedades, así como del sistema internacional. Buscan construir sus sociedades en función de las necesidades individuales y a base de los principios de democracia, imperio de la justicia social como meta del progreso económico y respeto a los derechos humanos. Internacionalmente, propugnan que las relaciones interestatales se estructuren sobre una base justa, que haya respeto por la independencia e igualdad de los Estados y que se dé una justa distribución de la riqueza (DIE).

A pesar de las afinidades con los Estados Unidos, estos lazos culturales "no impiden la determinación de los Nueve de consolidarse por sí mismos como una entidad distinta y original" que trata de desarrollar el vínculo atlántico "sobre una base de igualdad".

Europa está decidida también a emprender una estrecha cooperación con otros países industrializados, principalmente en el marco de la OGDE. Con la Unión Soviética y los paúses de Europa Oriental trata de fortalecer la política de distensión y cooperación $y$, al mismo tiempo, intensificar sus relaciones con la Ghina.

La posibilidad de afiliación a las Comunidades para otros países europeos que compartan los "mismos ideales y objetivos" se halla abierta, $y$ es un asunto de gran interés comunitario. En un segundo plano, se otorga importancia a la asociación con terceros países, dentro de una política comercial y de ayuda al desarrollo de alcance mundial. Los países europeos consideran que no puede existir verdadera paz en el mundo si las naciones industrializadas no prestan una mayor atención a los países en desarrollo. En este sentido, las Comunidades persiguen implantar arreglos con los países de la Cuenca Mediterránea, del. Medio Oriente y de Africa, con miras a fortalecer los antiguos lazos de Europa con estos países. De manera 
similar, las Comunidades desarrollarán sus relaciones con los pał́ses asiáticos y latinoamericanos (DIE).

Los rasgos más notables de estos principios de carácter general son su énfasis en la independencia y la igualdad de Europa con reIación a los Estados Unidos y la alta prioridad que adscriben a la formulación de una política común hacia el Tercer Mundo, aunque condicionada por consideraciones históricas y geográficas.

\section{Capacidades Económicas}

Siete de los nueve Estados europeos constituyen sociedades industriales o altamente modernizadas (Italia tiene una estructura dualista e Irlanda es una excepción, pues se trata de una sociedad en proceso de modernización). Por consiguiente, los países europeos comparten mayormente ciertos rasgos distintivos relacionados con su etapa de desarrollo económico.

Los gobiernos europeos juegan un importante rol en la economía y sus metas tradicionales de poder y seguridad han sido expandidas, en virtud de la disponibilidad de recursos y las crecientes expectativas de la ciudadanía, incorporando objetivos de riqueza económica y bienestar social. La orientación de las políticas exteriores también ha seguido este patrón, subrayando la importancia de los asuntos económicos e inclinándose hacia la cooperación internacional. La integración económica, en particular, ha demostrado ser un fructífero instrumento para la obtención de ciertos objetivos nacionales por parte de los gobiernos europeos.

Las óptimas condiciones para el intercambio económico internacional brindadas por el Sistema de Bretton Woods permitió que se desarrollaran, de esta manera, consistentes conjuntos de vínculos económicos y financieros entre los países europeos y otros países industrializados. Particularmente con los Estados Unidos, surgió una nueva interdependencia, en la cual las transacciones económicas involucraban apreciables costos o beneficios para ambas partes e imponían restricciones a las políticas gubernamentales, en una relación que no siempre operaba simétricamente, como veremos más adelante.

El crecimiento de la interdependencia se reflejó en un marcado incremento de las exportaciones como porcentaje del producto nacional bruto entre 1960 y 1974 para los países industrializados, como podemos apreciar en la Tabla I. Pero la interdependencia fue bastante más allá del comercio, aumentando los niveles de mano de obra extranjera, turismo, transferencia de tecnología y transacciones financieras en los países del Norte. 
LAS EXPORTACIONES GOMO PORGENTAJE DEL PNB

\begin{tabular}{lcc} 
& 1960 & 1974 \\
\hline Alemania & 15.7 & 23.1 \\
Bélgica & 31.8 & 42.9 \\
Canadá & 15.0 & 23.1 \\
Estados Unidos & 4.0 & 7.0 \\
Ttalia & 10.3 & $16.1^{*}$ \\
Reino Unido & 14.1 & 23.0 \\
\hline
\end{tabular}

*1973.

FuENTE: Schmid (1976).

El patrón de transacciones entre Estados Unidos y Europa, que tenía al primero principalmente como proveedor de capitales y tecnologías y a la segunda como receptora que ostentaba una mano de obra altamente calificada y considerables mercados, experimentó un significativo cambio a fines de la década del 60, tal como hemos visto en la primera parte (Morse 1976, Schmid 1976).

Además de los problemas de balanza de pagos que tenía entonces Estados Unidos, de la competitividad de las exportaciones europeas y otros acontecimientos políticos que ya hemos analizado, se daban en este momento en los países europeos problemas económicos y sociales propios de su etapa de desarrollo, los cuales precipitaron la crisis en las relaciones atlánticas. Los gobiernos europeos se hallaban presionados por el desenvolvimiento de conflictos sociales y laborales relacionados con reclamos de redistribución de la riqueza por parte de amplios sectores de la población, que exigían una justa participación en los frutos de la producción (Schmid 1976). Estos reclamos se vieron exacerbaidos por los efectos del alza de los precios del petróleo y forzaron a los gobiernos a reaccionar con medidas que perjudicaron la interdependencia. Se adoptó medidas de aislamiento de las economías nacionales, tales como control de los movimientos de capital y restricciones al funcionamiento de las empresas multinacionales, las cuales afectaron en alguna medida al propio proceso de integración europeo, pero, fundamentalmente, vulneraron los intereses norteamericanos.

En este momento ya Estados Unidos había demostrado elocuen- 
temente su reticencia a continuar apoyando el sistema económico internacional en medio de las reglas de juego vigentes y se había situado en una posición antagónica a las Comunidades Europeas. EI balance de costos y beneficios de la relación interdependiente de los países industrializados se hallaba en plena discusión y proceso de reajuste cuando la recesión trajo a los países europeos una dolorosa conciencia de las limitaciones que pesaban sobre sus políticas económicas, y por ello decidieron sacudirlas.

El lado conflictivo de la interdependencia se hizo bruscamente manifiesto a través del Atlántico. En medio de las cambiantes condiciones de la economía internacional y bajo crecientes presiones domésticas, la pugna de los gobiernos por mantener los "pedazos de la torta" que cada uno recibía fue muchas veces dura y áspera durante 1973 y 1974. Desde entonces han aparecido continuamente indicios de un resurgimiento global del proteccionismo en ambos lados del Atlántico - del despunte de una nueva era de mercantilismo. En verdad, el proteccionismo de Europa y Estados Unidos no se dirigía solamente a sus respectivas exportaciones; las barreras arancelarias y no arancelarias se levantaban también en gran medida para frenar las importaciones de manufacturas procedentes de algunos países en desarrollo que, sustentados en una mano de obra barata $y$ asociados con capital internacional, estaban llegando a amenazar la viabilidad de varias industrias europeas.

El hecho es que la interdependencia se desarrolló durante un periodo de creciente prosperidad, cuando los Estados Unidos, actuando como líder liberal, no percibian ningún desafío a su hegemonía económica y existía energía barata para todos. En cuanto el espiral de la prosperidad económica desapareció y se presentó un reto a la hegemonía norteamericana, el crecimiento de la ințerdependencia se detuvo. Entre los fenómenos que contribuyeron a aislar las economías nacionales del mercado internacional, en detrimento de la interdependencia, se dieron controles sobre los movimientos de capital, creciente oposición al poder de las empresas multinacionales, restricciones a la mano de obra extranjera y caída de algunas reglas básicas del sistema monetario. Puesto que las líneas tradicionales de interdependencia, vale decir aquellas sostenidas por las transacciones a través del Atlántico, fueron las más afectadas, los países europeos comenzaron' una activa búsqueda de nuevos vínculos económicos que les permitieran satisfacer la considerable proporción de sus objetivos que dependía del sistema internacional.

Europa es altamente dependiente de sus importaciones y exportaciones y no puede seguir un curso de autosuficiencia o autarquía. La única opción realista para las Comunidades Europeas dentro del sistema internacional es una meditada estrategia de interdependencia, en la cual elijan un conjunto adecuado de relaciones mutuamente dependientes. 
Especialmente en el rubro de materias primas, Europa depende del exterior para obtener un $75 \%$ de sus necesidades, porcentaje que se compara muy desfavorablemente con el $15 \%$ de Estados Unidos en este rubro. Europa es totalmente dependiente del exterior para minerales como manganeso, cromo, cobalto, platino, tungsteno y vanadio, dependiente en un $75 \%$ para hierro, y muestra también un alto índice de dependencia en cuanto a cobre, bauxita y magnesio. La mayor parte de las reservas mundiales de estos minerales, se encuentran en la Unión. Soviética y en el sur de Africa.

Las debilidades de la estructura económica de los estados europeos se hicieron patentes una vez que sus colonias obtuvieron la independencia. En este trance la integración económica y la complementación transatlántica sirvieron como medios para superar la escasez de recursos de Europa y conseguir altas tasas de crecimiento durante las décadas del 50 y el 60 . Pero, bastó que las etapas más dinámicas de la integración económica quedaran atrás para que aparecieran problemas de distribución a nivel nacional e internacional, que dificultaron aún más el crecimiento. Esta situación coincidió con el surgimiento de nuevos competidores industriales del Tercer Mundo en el campo del comercio internacional y motivó una marcada declinación de la participación de Europa en la producción mundial a través de la década del 70, así como perspectivas de una mayor declinación en la década del 80, debido sobre todo a problemas de ajuste y organización industrial característicos de los países europeos, según la opinión de la OCDE (OGDE, 1979).

\section{LA TESIS DEL "DESAFÍO EXTERNO"}

Las dos orientaciones fundamentales de las acciones externas de Europa, vale decir la búsqueda de independencia e igualdad en relación con los Estados Unidos y la política común hacia el Tercer Mundo, pueden relacionarse entre sí y ser mejor comprendidas visualizando un amplio proceso de unificación europea en una perspectiva histórica, gobernada por la modalidad desafío-respuesta, que presenta Alting Von Geusau (1974). Este autor afirma que Europa viene siguiendo un secular proceso de unificación, el cual se desarrolla principalmente a través de una serie de respuestas a desafíos externos.

Enfocando el período de postguerra hallamos que hay por lo menos dos difundidas explicaciones de índole política de la integración europea que comparten este enfoque: una que considera el proceso como una respuesta a una amenaza externa, la Unión Soviética y otra que lo considera una reacción frente a las recientes traumáticas experiencias de ruptura del sistema regional. Ambas explicaciones pueden complementarse con la tesis funcionalista, la 
Javier Alcalde / La crisis de las relaciones atlánticas y la formación de un...

cual señala que el proceso de integración, una vez en marcha, sigue primordialmente la dinámica interna de la lógica del "rebasamiento" (spillover), y de la expansión sectorial, asegurando su continuidad.

El problema de las dos primeras explicaciones radica en que no toman en cuenta las cambiantes características del sistema internacional y de esta manera soslayan el hecho que, a partir de 1945, el ámbito externo ha sufrido ciertas transformaciones que han modificado la naturaleza del desafío para la unificación europea.

Una de las más recientes transformaciones del sistema internacional tuvo lugar en 1970, cuando Nixon, motivado por razones que ya hemos mencionado, anunció al Congreso de Estados Unidos y al mundo el comienzo de una nueva era en la política exterior norteamericana, en la cual el interés y no la ideología iban a constituir la base para la acción internacional. Nixon estimó que el aparente abandono del empeño de una revolución mundial por parte de las potencias comunistas abría el camino para un nuevo orden económico internacional que pudiera fundarse más genuinamente en un equilibrio de los intereses nacionales de los principales actores.

La nueva actitud de Estados Unidos, intentando imponer nuevas condiciones a su hegemonía en Occidente, significaba en buena cuenta que al haberse podido conseguir algún tipo de equilıbrio en la balanza político-estratégica entre la Unión Soviética, China y Estados Unidos, este último se sentía libre para buscar también un nuevo equiliprio en la balanza económica mundial; que comprendía a él mismo, Europa y Japón. En el escenario resultante, Europa y Japón aparecían como los más importantes adversarios de Estados Unidos, pugnando con él el reajuste del sistema económico internacional a la luz de sus competitivos intereses. Aunque sin alterar su alianza dentro de la balanza estratégica, estos tres actores tácitamente aceptaron una vez más emprender una competencia de política de poder, en la cual la tónica era la sorpresa y la acción unilateral, como hemos descrito en la primera parte de este trabajo.

De esta forma el desafío externo cambió para Europa, debido al viraje de la política exterior norteamericana y a la aceptación por parte de la Unión Soviética y China de participar en el nuevo equilibrio, por lo menos parcialmente. Frente al desafío de la política de poder de Estados Unidos y a sus acciones económicas unilaterales, Europa asumió un comportamiento con una mayor orientación hacia la política de poder y concentró sus esfuerzos en las relaciones externas, cohesionándose contra Estados Unidos.

En este trance, los Estados Unidos actuaron una vez más como una suerte de motor para la unificación europea. Durante los años 50 el liderazgo norteamericano fue determinante para la decisión europea de buscar la unificación a través de la integración econó- 
mica. Las particularidades del proceso de integración agregaron la fuerza de su dinámica interna a los desafíos históricos originales que motivaron la suscripción de los tratados. A fines de los 60 , cuando la "Iógica" interna de expansión de la integración se agotó, sus mecanismos ya habían creado una entidad de gran fortaleza económica. La reacción estadounidense frénte a la competitividad del Mercado Común dio Iugar a un nuevo desafío para Europa, la cual turo que organizarse para actuar ya no frente a un benevolente líder, sino frente a un calificado adversario. Hasta aquí corre el argumento de Geusau.

Por otro lado, debemos xecordar que los países europeos tuvieron que erifrentar una amenaza proveniente de un estrato inferior del sistema internacional, con la emergencia de los nuevos países industrializados, los cuales en la década del 70 aumentaron su participación en la producción industrial y en el ingreso mundiales, a expensas de la declinación de Europa.

En resumidas cuentas, los estados europeos se vieron forzados a contemplar el diseño de una estrategia común para defender su posición de privilegio dentro del mundo capitalista, que estaba seriamente comprometida por su escasez de materias primas, por las nuevas condiciones de la hegemonía norteamericana y por el creciente poder económico de algunos países del Tercer Mundo, asociados con capitales japoneses y norteamericanos.

\section{Gonstrucción deL "Gentro" europeo}

El rol empresarial de los Estados Unidos para Europa entre 1945 y comienzos de la década del 70, dentro del cual prové́a mecanismos de defensa e instrumentos monetarios al Viejo Múndo, puede visualizarse formando parte de un esquema de relaciones entre un "centro" y una "periferia". Este conjunto característico de relaciones, originalmente formulado por Raúl Prebisch a comienzos de los años 50, ha sido desarrollado tanto en el análisis neo-marxista (teoría de la dependencia), como en el análisis ultra-Keynesiano $y$, aunque mayormente referido a los vínculos entre el mundo industrializado y los países en desarrollo, parece también adecuado para aplicarse a este periodo de las relaciones norteamericano-europeas (Morse 1976). En verdad, dependencia en un sentido amplio quiere decir simplemente relación entre dos economías o grupos de economías en la cual el desarrollo de una parte carece de autonomía y se halla condicionado por el desarrollo de la otra (Roxborough 1979). La dependencia en este caso es equivalente a una interdependencia marcadamente asimétrica, en la cual las políticas adoptadas por una parte afectan a la otra mucho más que las políticas de ésta a aquélla.

El argumento desarrollado por los ultra-Keynesianos parte de 
una tendencia de las naciones a agruparse alrededor de ciertas áreas donde existe una concentración de capitales y tecnología; estos núcleos poseen tasas elevadas de crecimiento económico que alimentan expectativas de recompensa económica a quienes se asocian con ellos (Deutsch 1957). En el proceso de crecimiento asociado que se suscita se hace claro que las mejoras que ocurren en el núcleo repercuten en última instancia en deterioro de la periferia, donde la habilidad de los gobiernos para alcanzar sus objetivos políticos y económicos declina, debido a la creciente influencia de los intereses económicos del "centro". En efecto, al mișmo tiempo que las empresas del "centro" van ocupando mayores proporciones de capital, gestión y mano de obra en la periferia, van también angostando la base económica para empresas independientes en ella.

Este fenómeno plantea una amenaza de extinción a los grupos empresariales de la periferia y reduce a los gobiernos a representar los intereses de la mano de obra, presentándoles el riesgo de perder su identidad política y ser integrados en una comunidad económicopolítica de mayor amplitud (Schmitt 1969).

Aparte de la decisión de integrarse formalmente al "centro", la única salida que tienen los gobiernos en esta situación es la de intentar crear ellos mismos un núcleo o "centro" de capital y tecnología. Fue esta la alternativa por la que optaron los gobiernos europeos en la década del 70, tal como lo expresaron formalmente los jetes de estado en la Gumbre de París (1972), cuando en el contexto de las Comunidades Europeas se otorgó primera prioridad a la creación de una Unión Económica y Monetaria.

En la práctica este "centro" europeo no fue creado de la nada. Desde los comienzos de la integración europea, autores como $\mathrm{Pe}$ rroux (1958) señalaban que el proceso tenía su eje en el Ruhr y en aquellas industrias directamente alimentadas por esta zona. Durante los años 60, Alemania era identificada como centro de gravedad del esfuerzo de integración europeo, ya que ostentaba las mayores tasas de beneficios y pagaba los salarios industriales más elevados de Europa. Durante los años 70, Francia alcanzó un destacado ritmo de crecimiento, guiada por el deseo de alcanzar a Alemania. En la actualidad, el centro europeo no se halla restringido a uno o dos países (no obstante mantenerse la superioridad industrial de Alemania sobre el conjunto) sino se extiende desde el norte de Italia hasta la desembocadura del Rhin e incluye también un sustancial aporte tecnológico de Gran Bretaña.

La decisión europea de los años 70 significó que los gobiernos se dedicaran a estimular el crecimiento de las empresas nacionales y que asumieran mayormente los costos necesarios para su transformación hasta que ellas consiguieran reducir la brecha tecnológica que las separaba de las empresas multinacionales norteamericanas. 
Con miras a reducir estos costos y a crear un bloque con suficiente poderío económico para tratar con los Estados Unidos en pie de igualdad, Europa vio la necesidad de formar una gran "coalición" (Morse 1976). La continua expansión de las Comunidades Europeas a partir de 1971, así como su llamada "Política Mediterránea", parecen responder a este imperativo de articular una amplia "coalición" de naciones y al deseo de desarrollar líneas alternativas a la interdependencia atlántica.

La crisis de la energía de 1973-74, combinada con la recesión mundial, por un lado, y la preocupación por el suministro de materias primas junto con las demandas del Tercer Mundo de un Nueyo Orden Económico Internacional, por otro lado, sirvieron para que la estrategia externa de las Comunidades Europeas incorporara dos nuevos objetivos. En efecto, Europa, al ver amenazado el suministro de petróleo e incierta la provisión de materias primas a largo plazo, optó por disminuir la importancia de la búsqueda de mercados para sus manufacturas y se concentró en asegurar el futuro de estos suministros vitales. Al mismo tiempo, la crisis mundial hacía evidente las precarias ventajas de los países industrializados como productores de manufacturas, habida cuenta de los crecientes costos de la energía y de la mano de obra, la estampida de los precios de las materias primas y la severa competencia planteada por los productos de los nuevos países industrializados. Las empresas multinacionales europeas se vieron así empujadas a internacionalizar sus. procesos productivos y los gobiernos europeos tuvieron que comenzar a considerar la reestructuración de las industrias nacionales, siguiendo ambos actores los pasos que norteamericanos y japoneses habían dado unos años antes.

Las reacciones europeas frente a la gran crisis de los años 70 fueron fundamentalmente distintas a las de Estados Unidos, debido a las marcadas diferencias de potencial económico existentes entre ambos. Europa no podía distraerse con una ilusión de autosuficiencia por un solo instante, por lo que se vio forzada a adoptar una actitud pragmática desde el inicio y a tratar de conseguir nuevos acuerdos con sus proveedores de petróleo y materias primas. A diferencia de los Estados Unidos, que pudieron dedicar algún tiempo a una controversia interna entre liberales y conservadores acerca de la desigualdad de las personas y las naciones y acerca de la respuesta que debían merecer las demandas de los países en desarrollo (Ajami 1978) y que no han tenido todavía la iniciativa de ninguna medida concreta hacia el Tercer Mundo, Europa diseñó una nueva relación con los países en desarrollo, iniciando en 1974 el diálogo euro-árabe y suscribiendo en 1975 la Convención de Lomé con un grupo de países de África, el Caribe y el Pacífico (Grupo $\mathrm{ACP}$ ), cambiando sustancialmente con este último instrumento el 
espíritu y contenido de la anterior Convención de Yaoundé que la ligaba con los países africanos.

Europa se percató de que a nivel mundial había ocurrido una redistribución del poder, la cual se manifestaba en un aumento sustancial de la participación del Tercer Mundo en inversiones (países de la OPEP), producción industrial (nuevos países industrializados) e influencia económico-política (asociaciones de productores de materias primas), en tanto que los países industrializados mantenían todavía una mucho mayor proporción de poder tecnológico.

Teniendo esto en mente, las Comunidades Europeas comenzaron una nueva línea de acción, buscando primero el acercamiento a los países árabes productores de petróleo, con lo cual trataron de consèguir abastecimiento de energía, así como inversiones.

El diálogo euro-árabe da lugar a un esquema de cooperación entre los dos grupos de países, el cual ha determinado que una serie de lazos económicos entre ellos crezcan remarcablemente a partir de 1974. Los países árabes siguen el propósito de conseguir modernizar sus economías en el período relativamente corto que puedan durar sus reservas de petróleo, aprovechando para ello la tecnología y la mano de obra calificada de Europa. Europa, por su parte, persigue no solamente tener garantizados sus suministros de petróleo al transformar su dependencia de los países árabes en este rubro en una relación interdependiente, sino también atraer inversiones árabes para atender los requerimientos financieros de la construcción de un "centro" propio. Actualmente Europa y el mundo árabe se encuentran ligados por un conjunto de arreglos intergubernamentales y privados sobre comercio y tecnología, así como por varios proyectos conjuntos de carácter oficial. De igual manera, la mayor parte de los excedentes provenientes del petróleo han sido transferidos a los mercados de capitales europeos (Calleo 1975, Taylor 1979). En el rubro de comercio, las Comunidades Europeas proveyeron en 1978 un 50\% de las importaciones de los países de la OPEP provenientes del mundo desarrollado, con lo cual alcanzaron un porcentaje mayor que Estados Unidos y el Japón juntos.

Sin embargo, el nuevo balance y base de entendimiento que la crisis de petróleo ha traído a la antigua relación entre Europa y el mundo árabe solamente podría convertirse en fundamento de una verdadera coalición interregional en la medida en que pudiera superar tanto el propósito estratégico de los Estados Unidos de controlar las relaciones occidentales con el Medio Oriente, como la reticencia europea a llevar adelante una mayor participación política y militar en la región. No obstante estas limitaciones, el diálogo euro-árabe constituye ya un importante logro de cooperación, al mismo tiempo que un exitoso paso para el reacomodo de Europa en el sistema económico internacional. 
Muy diferentes son, en cambio, las actitudes y los vínculos de Europa con el resto del Tercer Mundo, en especial con el grupo ACP, con el cual, pese a las innovaciones que ha traído la Convención de Lomé y a los visos de interdependencia que se quiere dar a la relación, existe una considerable asimetría de oportunidades y beneficios, explicable por la enorme desigualdad en poderío económico de los dos grupos de actores. Pero este tema merece tratarse en un trabajo aparte.

AJAMr, F. (1978), "The global logic of the neo-conservatives". World Politics, July.

Boletin de las Comunidades Europeas 1973 (12).

Boletín de las Comunidades Europeas: Suplemento $1 / 76$.

Bucran, A. (1974), The end of the post-war era. Weidenfeld - Nicolson.

GaLleo, D. (I975), "The European coalition in a fragmenting world. Foreign Affairs, October.

CANTORI \&: SPIEgeL (1970), The international politics of regions. Prentice Hall.

Deutsch, K. (1957), Political communities and the North Atlantic area.

GeUSAU, FAV. (1974), The external relations of the EG. Saxon House.

HAAs, E. (1976), "Turbulent fields and the theory of regional integration.
International Organization 30 (2).

Hudson, M. (1977), Global Fracture. Haxper \& Row.

Morse, E. (1976), "Interdependence in world affairs". (In Rosenau et al. World Politics. Free Press).

OCDE (1979), Facing the future; mastering the probable managing the unpredictable.

RoxbOROUGH, I. (1979), Theories of underdevelopment. Macmillan.

Scrimr, G. (1976), "Interdependence has its limits". Foreign Policy. 21.

SchmrT, H. (1969), "Integration and conflict in world economy". Journal of Common Market Studies. September.

TAYLOR, P. (1979), When Europe speaks with one voice. Aldwych Press. 